\title{
Decentralization's impact on the health workforce: Perspectives of managers, workers and national leaders Riitta-Liisa Kolehmainen-Aitken*
}

\author{
Address: Management Sciences for Health, Boston, Massachusetts, USA \\ Email: Riitta-Liisa Kolehmainen-Aitken* - rlkaitken@msh.org \\ * Corresponding author
}

This article is available from: http://www.human-resources-health.com/content/2/1/5

(C) 2004 Kolehmainen-Aitken; licensee BioMed Central Ltd. This is an Open Access article: verbatim copying and redistribution of this article are permitted in all media for any purpose, provided this notice is preserved along with the article's original URL.

\begin{abstract}
Designers and implementers of decentralization and other reform measures have focused much attention on financial and structural reform measures, but ignored their human resource implications. Concern is mounting about the impact that the reallocation of roles and responsibilities has had on the health workforce and its management, but the experiences and lessons of different countries have not been widely shared. This paper examines evidence from published literature on decentralization's impact on the demand side of the human resource equation, as well as the factors that have contributed to the impact. The elements that make such an impact analysis exceptionally complex are identified. They include the mode of decentralization that a country is implementing, the level of responsibility for the salary budget and pay determination, and the civil service status of transferred health workers.

The main body of the paper is devoted to examining decentralization's impact on human resource issues from three different perspectives: that of local health managers, health workers themselves, and national health leaders. These three groups have different concerns in the human resource realm, and consequently, have been differently affected by decentralization processes. The paper concludes with recommendations regarding three key concerns that national authorities and international agencies should give prompt attention to. They are (I) defining the essential human resource policy, planning and management skills for national human resource managers who work in decentralized countries, and developing training programs to equip them with such skills; (2) supporting research that focuses on improving the knowledge base of how different modes of decentralization impact on staffing equity; and (3) identifying factors that most critically influence health worker motivation and performance under decentralization, and documenting the most cost-effective best practices to improve them. Notable experiences from South Africa, Ghana, Indonesia and Mexico are shared in an annex.
\end{abstract}

\section{Introduction}

Decentralization, in its various forms, is now a common feature of reform in both developed and developing countries. It is, however, rarely the only reform measure that a particular country is engaged in. Decentralization is often accompanied by profound changes in the way publicly- funded services are resourced, and human, financial and material resources managed. The extent to which health leaders participate in designing and planning how and to whom responsibility and authority will be transferred varies, but experience at country level shows that technical health expertise has not been adequately utilized in these 
reforms. This is particularly true of the many countries where the impetus to transfer power away from the center stems from political, as opposed to health sector, concerns.

Reallocation of roles and responsibilities always affects the health workforce and the way it is managed. This is true irrespective of the extent to which health leaders are allowed to shape the decentralized structures and management systems. Concern has been mounting among health managers and workers about the impact that decentralization has had on human resources for health $(\mathrm{HRH})$ and the way they are managed. Attention to this issue has, however, been lacking outside the health sector itself. Dussault and Dubois echo the concerns of many observers, when they comment, "In many reforms, there is discordance between the elevated attention given to issues of financing and structural transformation and the low attention given to HRH issues..."[1]. One consequence of this lack of attention is that experiences and lessons of different countries have not been widely shared.

This paper aims to examine evidence from published literature on decentralization's impact on the demand side of the human resource equation, and the factors that have contributed to this impact. The main focus is on the experience of developing countries, but evidence from other countries is also considered, as appropriate. The paper starts by cataloging the various elements that make an impact analysis of this type exceptionally complex. The main body of the paper is devoted to examining decentralization's impact from three perspectives: that of local health managers, health workers themselves, and national health leaders. This analysis aims to focus on the big picture view, highlighting the most important areas. While the emphasis is on the demand side, the analysis does not totally ignore supply side issues, acknowledging that demand and supply are intricately interlinked. The paper concludes with recommendations regarding three key concerns that require prompt attention and collaboration between national authorities and international agencies. Notable experiences from South Africa, Ghana, Indonesia and Mexico are described in an annex, as these countries grapple with human resource implications of decentralization.

\section{Analytic complexity}

A full analysis of decentralization's impact on human resource management in the health sector would require a multidimensional Rubik's cube. A multitude of factors influence both decentralization's impact and the health sector's response. First and most obvious of these is the mode of decentralization that a country is implementing. As Wang et al. point out, "...the different organizational forms of decentralization will provide structural frame- works leading to different degrees of autonomy of HRM [human resource management]"[2]. Second, the location of responsibility over the salary budget of health workers has a large bearing on the way decentralization impacts on them. A third set of factors consists of the way that reforms deal with the civil service system and health workers' participation in it. Other important factors include:

- size of the country

- socioeconomic status of the country

- legal and regulatory rigidity of the civil service system

- significance of the public sector as an employer in the health sector

- power of labor unions

- influence of professional associations

- historical patterns in the way health services are organized and managed.

\section{Modes of decentralization}

Decentralization options adopted by countries include:

- deconcentration to lower levels within a national ministry structure

- delegation to semi-autonomous bodies, such as hospital or local health boards

- devolution to separate local governments

- privatization to NGOs and for-profit organizations.

Multiple modes of decentralization are generally found in the same country, and implemented at the same time. Decentralization may cover all or only some of the health programs and services that the public sector provides. For example, communicable disease control programs may continue to be run vertically from the center, while other primary care programs are decentralized. Donor-funded programs are also likely to remain under central control. Furthermore, the allocation of new roles and responsibilities is commonly expressed in quite general terms. This lack of detail and clarity allows for multiple and varying interpretations by managers at different levels of the health system.

\section{Responsibility over the salary budget and pay determination}

Salary budget may be: 
- determined at the central level for all staff and transferred to decentralized units as a separate salary budget

- incorporated in a grant from the national government to the decentralized units

- determined centrally and transferred to decentralized units as a salary budget for seconded civil servants, and determined and funded by decentralized units for local hires.

Systems of pay determination are traditionally highly centralized in most countries. As Bach points out, "For governments there is an understandable reluctance to delegate significant autonomy for pay determination to lower organizational levels because of the desire to maintain tight control of the public sector pay bill"[3]. Appropriate roles of central and local levels in determining staff pay remain controversial. As Wang et al. point out, "...complete autonomy of local determination [of staff pay/salaries] is rare and staff pay is often a combination of both local and central influence"[2].

\section{Civil service options at decentralization}

The rigidity of a centrally managed civil service, including the inflexibility in pay structures, is a concern the world over. The nature and extent of a country's reform process dictates, however, whether decentralization is accompanied by any attempt to change health workers' incorporation in the civil service. Decentralization of powers over the health system thus may or may not be accompanied by a corresponding decentralization of human resource management responsibilities.

Countries have defined the civil service status of transferred staff in the public sector health workforce in four main ways:

- Retain a uniform national civil service: Health workers are seconded or transferred to decentralized units (e.g. districts) under centrally defined civil service terms (e.g. Papua New Guinea and the Philippines)

- Decentralize the national civil service: Health workers are transferred to decentralized units, with civil service processes also decentralized to newly created local-level public service commissions (e.g. Uganda)

- Mixed model: Old employees are seconded to decentralized units under the national civil service with centrally defined terms. New hires are employed directly by the decentralized units under locally defined terms (e.g. Jamaica)
- Remove health workers from the national civil service: All public sector health workers become employees of a "national health service" with its own terms and conditions of service (e.g. Ghana), or transferred staff are "delinked" from it with local terms and conditions of work (e.g. Zambia).

\section{Perspective of local health managers}

Local health managers have a range of new responsibilities, depending on the powers that have been decentralized to them. Under devolution, they are accountable to the local political head, such as a municipal mayor or a provincial governor. Under delegation, the local health manager may be accountable to a district health board or a hospital board. The national-level health authority, however, often continues to issue directives to local health managers, particularly in the early days of decentralization. This can make it very difficult for local managers to know who they should actually respond to!

Local health managers have three main concerns in human resource management, regardless of their span of responsibility. They want to staff their facilities or services appropriately. They want their employees to perform well and be productive at work. They want well-functioning routine personnel administration systems in order to improve efficiency and minimize labor conflicts.

\section{Staffing services}

Decentralization makes local health managers responsible for improving the way health services are targeted to meet priority health needs, organized, and managed within the available budget. To do this, they need a workforce whose staff numbers and mix are as appropriate as possible to these needs, and whose cost is affordable. To foster the development of such a workforce, the manager needs to: (a) revise, as necessary, the existing personnel structure, (b) staff the structure with the most appropriate health workers, and (c) keep payroll costs under control.

Analyzing the current staffing situation and planning its improvement are essential steps in revising the personnel structure. With new responsibilities having been transferred to the decentralized level, a more appropriate personnel structure might require the creation of new types of jobs, re-profiling of old ones or the addition or abolishing of staff positions in accordance with need. What proof do we have that this is taking place in decentralized countries?

Literature on low- and middle-income countries provides little evidence that decentralization has resulted in creation of new posts, job re-profiling, or an improved staff mix [2]. A tightly centrally-controlled civil service may not allow local managers to create new posts, or their budget 
may be insufficient to increase staffing levels, even if they have this power. Planning skills, particularly human resource skills, are generally weak at the peripheral level in most developing countries. Human resource planning responsibilities are often transferred to local managers without providing them with adequate skills for these roles. Human resource databases frequently deteriorate as a result of decentralization, further hindering local and national planning $[4,5]$. In the United Kingdom, a review of historical staffing patterns did take place after decentralization to the NHS trusts, but as Buchan reports, this created a tension between local health managers concerned about costs, and health professionals whose main interest was patient care [5].

Local health managers want staff to be recruited and appointed without undue delay, and only the best-qualified candidates to be selected. The ability to transfer staff between geographic areas and health facilities, as needs change, is also important. The extent to which local health managers can influence the recruitment and appointment of qualified candidates depends on the type of decentralization, the nature of the country's public service system, and the degree of financial autonomy that the local level has for paying staff. Wang et al. point out that deconcentration is unlikely to transfer recruitment and hiring to the local level, while delegation and devolution are most likely to involve a more extensive transfer of these responsibilities [2]. Restrictions to timely recruitment and hiring from centrally set human resource budget ceilings and legislative controls are common concerns of local health managers. They also complain about political interference and nepotism in hiring decisions [6-10].

By increasing local authority and introducing flexibility in hiring practices, decentralization can change the nature of the labor market. The result is rising competition for staff between decentralized units. A serious concern for managers in poorer areas of many countries is the lack of effective mechanisms at their disposal for attracting and retaining staff [11].

Local managers, concerned about their budget, are interested in finding ways to curtail labor costs by controlling salary levels. Their autonomy to do so is, however, restricted by centrally determined pay limits, nationally unified salary scales and packages, and overall budget ceilings. Because of these constraints, local managers are keen to find ways to convert fixed salary costs to variable costs through flexible employment arrangements, such as timebound contracts. New payment mechanisms, such as merit- and market related pay and special bonuses are emerging in Western and Eastern Europe and also in Latin America $[12,13]$. They remain controversial, and there is little information on their short and long-term impact.

\section{Employees' performance and productivity}

To improve the performance and productivity of health workers, local health managers need to assess staff performance, supervise employees, and respond appropriately to identified performance gaps. Local managers are also responsible for ensuring that employees have the necessary resources and tools to do their job. Performance and productivity are influenced by staff motivation, another concern of the manager. Attending to all these issues appropriately is a considerable challenge in resource poor settings, where decentralization has thrust management responsibilities to managers who are inexperienced in human resource management.

Martinez and Martineau point out that effective performance management is rare in public services in developing countries, because its prerequisites (such as a living wage for health workers, and the availability to them of drugs, equipment and transport) are often missing [14]. The systems used to appraise staff performance are frequently outdated or poorly understood by local staff $[15,16]$. In many developing countries, decentralization has confused supervision responsibility, diminished technical supervision capacity, and reduced the number of supervision visits $[17,18]$. Part of this confusion is the result of some health programs being decentralized, while others remain central responsibilities. Even when all programs are decentralized, old program allegiances of staff create tension and potential conflict between the supervisees and the new local health manager.

Decentralization brings considerable new skill needs, particularly in management competencies. Local managers' capacity to respond to these and other performance gaps through training is, however, restricted. They lack funds to pay for such training, and often have little or no capacity to plan and implement in-service training programs at the local level [19].

There is evidence that in a number of countries, decentralization has compromised the ready availability of drugs, supplies and transport that are essential for good staff performance and productivity $[20,21]$. This has been the result of more complex procurement systems and funding cuts to local health budgets.

Staff motivation has been affected through rapid change, and the perception of health workers that their compensation levels and working conditions have been negatively affected by decentralization. Bach emphasizes that managers have paid insufficient attention to addressing such issues as working hours, working conditions and career structures that can have an significant long-term effect on staff performance and morale [22]. 


\section{Managing personnel}

Van Lerberghe et al. observe that "...there is no evidence for an automatic link between decentralization and more effective management of human resources..."[23]. In most developing countries, local health managers do not have staff adequately trained in personnel administration, nor do they have simple but robust systems for managing personnel affairs. A decentralized personnel management study in Uganda, for example, indicated that "personnel management structures and systems at the district level are weak, personnel offices inadequately staffed, the District Service Commissions poorly resourced, and central-local linkages still in need of clarification"[15].

Untrained managers and weak personnel systems are ill equipped to cope with the added complexity that decentralization brings to personnel administration. The move to flexible employment arrangements, particularly in Latin America, has fragmented the workforce. The decentralized unit is now responsible for personnel administration of many different types of staff: those who are locally hired, those who are part of the national civil service, those hired on contract-terms, etc. Brito reports that in Brazil, for example, there are now more than 15 different ways of hiring a health worker to work in the public sector [24].

\section{Perspective of health workers}

Health workers respond positively to the human resource demands of a decentralized unit if they seek employment in it, accept a post if it is offered, and remain in service. Their ability and willingness to act in response to local demands depend on a number of factors. These include a worker's personal family and economic situation, attractiveness of salary levels and other terms and conditions of service, opportunities for professional growth and career development, alternative employment opportunities in the labor market, the level of morale and motivation in the workforce, etc. Among these factors, stability of employment, salaries and working conditions, and professional development opportunities are emerging in the literature as very important concerns of health staff.

\section{Stability of employment}

Most health workers value job security highly. If their employment status changes from national civil servants to local employees, they want to maintain at least the level of benefits, seniority, and status that they had before decentralization. They prefer minimal changes in the location of their work, job content or reporting relationships.

Decentralization and accompanying reform processes have brought an increased level of instability to employment. In countries of the Latin American region, "rationalization" of public sector personnel has resulted in a massive reduction of staff through separation, early retirement, merging of staff posts, etc. ILO reports that overall "there have been significant increases in the numbers of people employed under more precarious forms of employment contract..." and that "...traditionally high levels of job security in the health sector have changed"[12]. While more flexible employment patterns are rapidly emerging in Latin American and Asian countries, they are still rare in Africa [12,24,25].

Decentralization is also changing the degree of civil service protection that health workers have against unfair hiring, disciplinary and work practices. National civil service rules no longer apply, when health workers are hired under local terms and conditions of service. Where power has been devolved to local governments, health workers are more exposed than before to local political pressures and demands, even if they remain part of the national civil service. Under privatization, health workers are governed under general private sector labor laws, and no civil service protections apply to their employment.

\section{Salaries, benefits and working conditions}

Adequate and equitable remuneration, timely payment of salary \& benefits, and satisfactory working conditions are very important for the performance, productivity and motivation of staff.

Levels of remuneration are affected by the budgetary realities of the decentralized unit and the bargaining power of the health workers. The economic crises that developing countries are struggling with mean that many are not able to afford a living wage to public sector employees. The role of unions in pay bargaining depends on historical patterns, as well as the extent to which privatization has been used as the mode of decentralization. Particularly in Western Europe, the introduction of market elements into the health sector has changed traditional bargaining systems. There is more negotiation at the decentralized unit level, and more individualized patterns of remuneration [12].

Decentralization can threaten the concept of equal pay for equal work. National employees may be compensated differently from decentralized employees. Tang et al. report that in China, personnel working in state-owned and devolved health centers are paid differently [26]. Evidence from the Philippines shows that salaries of devolved health workers decreased in the early years of devolution to local government units [9]. As decentralized units are given more financial autonomy, and as flexibility in pay bargaining increases, health workers doing similar jobs but in different decentralized units will be remunerated differently. This is emerging in Uganda, where salaries are set nationally but staff benefits and allowances locally 
[27]. Considerable differences in salary levels and other terms of employment have also emerged in South Africa, where salary levels are determined locally. [Personal communication with Dr. Jon Rohde.]

Pensions have arisen as an important issue for health workers in countries such as Zambia, which have tried to break the rigidity of the civil service system by making health workers local employees. Public sector employees are usually included in a large national pension scheme, covering all civil servants. The contributions are paid by the national government, and are part of benefit packages that have been negotiated with labor unions. Under devolution, local authorities may be reluctant or out-right refuse to accept the financial burden of paying for the pensions of prior civil servants. Thus, a new pension fund to cover local employees may be needed. In Jamaica, for example, regionally hired health workers now belong to a private pension fund. Contributions to it come both from the regional health authority and the individual employee. Previously, the government paid the total contribution.

Delayed payment of wages or their non-payment is a serious issue for decentralized health workers in the poor countries of the developing world. It has also happened in Central and Eastern Europe, as the countries of this region have tried to cope with economic crises [12]. Staff whose salaries are centrally distributed, such as those working for delegated hospitals, are more likely to get their salaries than those employed by devolved units. The latter may not be paid for months or do not receive their full pay when they are paid $[9,28]$.

There is very little in the literature about decentralization's impact on working conditions in the developing world, other than observations, referenced before in this paper, that financial restrictions have reduced availability of essential drugs, supplies and transport. ILO comments that overtime and unsociable working hours have increased as a result of reform processes and cost-containment measures in countries, such as France, Germany, Sweden and the United Kingdom. In addition, the intensity of work has increased greatly, even if the actual hours of work have not changed much [12].

\section{Professional development}

Access to skill development opportunities and career mobility are very important for health workers. Health managers, especially in smaller health systems, have conflicting attitudes. They want to be able to fill their posts with appropriately trained people, but may be reluctant to release their staff to gain the extra training. Staff shortages in such health systems may be so severe that there is no one to cover for the health worker who does go away for training.

Published literature includes few examples of improved professional development opportunities as a result of decentralization. In many resource poor countries, decentralization has instead reduced the prospects for developing and maintaining skills. Reduced training budgets, isolation from national training opportunities and weak local training capacity are all to blame for the lack of appropriate capacity building opportunities.

Career mobility has become more restricted, particularly in devolved settings. The traditional career path from primary to higher levels of care and from lower to higher levels of administration is no longer as feasible as before. Many factors are at play: complexities of transferring between decentralized units, or from the decentralized to the national level, fractured or non-existent information channels about job opportunities, skill levels that are getting outdated because of the scarcity of training opportunities, etc.

\section{Perspective of national leaders}

The role and responsibilities of national health leaders in the human resource arena change when key human resource decisions are transferred to the decentralized level. The old role of the national ministry of health was mainly focused on routine personnel administration and in-service training. As these functions are transferred to more peripheral levels, the central level must assume new but vitally important policy, planning, normative, and regulatory functions. Four areas emerge as critically important roles in the human resource realm. They are:

- Strategic long-term planning and resource management for the health workforce

- Regulating the entry to and conduct of professional training and practice

- Vigilance for staffing equity between decentralized units, and

- Legal protection of staff.

To exercise these roles, the national ministry of health requires a strong capacity in modern concepts of human resource management. It must develop good relations and functioning mechanisms of cooperation with key stakeholders, such as heads of leading training institutions and representatives of professional associations. Published literature provides little evidence that decentralizing countries would have either fully grasped the importance of the 
above-mentioned four roles or developed the requisite human resource capacity to assume them effectively.

\section{Strategic human resource planning and resource management}

National government leaders have the responsibility to take a strategic, long-term view about the preparation of human resources to meet the emerging needs and opportunities. Health needs are not static. Epidemiological and technological transitions, new and emergent diseases, the growth of private practice, and changing patient expectations all alter the demands placed on the health sector. As Biscoe underscores, "HR strategies should be initiated at the national level where it is in the national interest to do so"[29].

Strategic human resource planning at the national level includes monitoring external and internal threats to the country's ability to maintain a stable and competent health workforce, well aligned with national health priorities [30]. Such threats come from many sources, e.g. increased out-migration of highly trained staff, reduced or inappropriate training outputs from private universities that are replacing publicly funded higher education institutions, loss of staff through HIV/AIDS, etc. Appropriate responses to such threats need to be devised and implemented in collaboration with national and local stakeholders.

With very few exceptions, "a generally very patchy picture of HR planning" emerges in the literature [22]. Human resource planning capacity, even at the national level, is weak, particularly so in developing countries. Data bases on staff numbers and skills were already inadequate in many countries prior to decentralization, but suffered further deterioration from it. Where planning has taken place, it has often been narrowly focused on certain occupations only. It has generally been oriented toward looking only at numbers, leaving "key questions about the distribution, qualifications, motivation, development, and performance of staff unexplored"[22].

The management of government and donor resources for in-service and specialty training is another important national government responsibility. This includes the identification and management of resources to meet the vast management training needs that decentralization carries with it.

\section{Regulating professional training and practice}

The national government is responsible for establishing good systems for accrediting training programs and for certifying graduates as having obtained either a basic or a specialty qualification. This regulatory and normative role of a national government in training is especially impor- tant in countries that have experienced a rapid growth of private institutions of higher education. Many of these institutions have been established with profit motives, and the training facilities and curricula may not conform to national standards [31].

Those establishing regulatory systems and implementing the regulatory practices must adopt a long-term view of human resource development. Strategic national human resource planning considerations must inform the development of regulations. The regulatory role of the national government must be exercised in close collaboration with professional associations. In seeking to effect change through regulatory practices, the national government needs to take account of the conservative nature of the professions, and anticipate a slower pace of change.

\section{Vigilance for equity in staffing}

The more that decentralization hands real power to local levels, the more equity will suffer, unless appropriate equalization mechanisms have been established. Managerial capacity and resource bases vary widely between decentralized units. Well-managed and well-resourced decentralized units will rapidly pull ahead of others. They will have higher staffing levels; offer better salaries, benefits, and career development opportunities; and provide more appealing working conditions than their resourcepoor or badly managed counterparts. The employees they attract will be more experienced and better qualified, and remain in service longer, further increasing the inequity of staffing.

National health leaders must vigilantly monitor emerging inequities in the quality and quantity of staffing between decentralized units. They must devise appropriate mechanisms to respond to such inequities. Finally, they need to develop these mechanisms in full consultation with local health managers and other stakeholders.

\section{Legal protection of staff}

Decentralization has generated a number of legal concerns for health workers. As local employees, what protection do they have against unfair hiring practices or unjust dismissal? What legal resources do they have, if they are sued for malpractice? Does the national malpractice insurance that covered them as national civil servants still apply when they are seconded or transferred to the employ of local governments? Addressing such important legal concerns is an important central government responsibility that requires the establishment or maintenance of appropriate mechanisms for legal protection of all staff on the public payroll. 


\section{Conclusion}

Those involved in designing decentralization generally come from outside the health sector itself. Thus, they have only a limited understanding and appreciation of matters related to the health workforce. Even those in the health sector rarely lavish the same degree of attention to human resource issues as they pay to issues of health financing and financial management. Such influences as globalization and the devastating epidemic of HIV/AIDS are now bringing human resources to increasing prominence in national and international deliberations. But as the evidence examined in this paper demonstrates, the longstanding disregard of the human resource arena has resulted in the emergence of several important and problematic challenges that impede the creation of an appropriately deployed, well-trained, and motivated workforce. These challenges are the concern of local managers, health workers and national leaders, and their resolution will require concerted action on several fronts.

Three issues, whose resolution calls for active collaboration between international and national authorities, stand out among the many that need prompt attention. The first is the urgent need to define the essential human resource policy, planning and management skills that national human resource managers working in decentralized countries must possess. The definition of these skills much be followed by the creation of appropriate training opportunities to acquire said skills. The right set of skills will equip national managers to competently steer the development of a country's total health workforce, and be capable of providing appropriate support to local-level managers in the human resource realm.

Decentralization's purported negative impact on staffing equity is the second issue. The emerging evidence about increasing staffing inequity is of great concern. Hard data to back up these concerns have, however, been difficult to gather because of problems with deteriorating data bases and the lack of appropriate research. The definition and implementation of evidence-based strategies to address equity concerns requires improving the knowledge base about the impact of different modes of decentralization on staffing equity, and the variables that are particularly beneficial or damaging in this regard. Critical research questions must be defined, appropriate research funded and implemented, and the results widely communicated.

Health worker motivation and performance is the third issue requiring urgent action. Anecdotal evidence from a large number of decentralized countries shows that the rapid changes and uncertainties associated with decentralization have had a disastrous impact on staff morale. Those factors that under decentralization most critically impact health worker motivation and performance must be identified, and the most cost-effective best practices to improve them documented and shared.

\section{Annex}

The following four country vignettes provide examples of successes and challenges in the HRH arena that decentralization has brought for local health managers, health workers and national leaders.

\section{South Africa}

The post-apartheid government in South Africa inherited a centralized, highly fragmented and inequitable health system. The government seeks to increase equity, efficiency, and community involvement by creating a unified, decentralized national health system, which is based on a district health system model. The development of such a decentralized district health system continues to face considerable human resource challenges.

One of the most daunting tasks has been the integration of health workers into a single district staff establishment. Doctors and nurses who now work in one district health system were previous employees of national, provincial, municipal or homeland governments. Their remuneration packages and service conditions varied widely, as did the legislations governing their work, and the organizational cultures and management styles under which they worked. Substantial differences have also become evident in the skill levels of health workers coming from such divergent backgrounds.

Other important decentralization-related human resource problems include:

- Lack of accurate and timely human resource information and functioning HR management systems at district and provincial levels (e.g. job descriptions, performance evaluation systems, etc.)

- Lack of authority of local managers to reallocate staff, create new posts or change the existing ones

- Mismatch between HR standards, set at the national or provincial levels, and the ability of disadvantaged districts to attract and retain staff to meet such standards

- Inequities in salary levels, terms of employment and continuing education opportunities, rising disparities in financial capacity and local budget allocations

- Pressure on local governments to award salary levels that they cannot afford, as a result of local labor negotiations in which unions compare salary awards of different local governments 
- Poor morale and lowered performance due to staff concerns about the security of their employment and limitations to their career development

Positive experiences include some managers' creative use of their decentralized powers, such as the decision to freeze salaries of health workers who took an extended, unauthorized absence, which achieved a dramatic improvement in staff discipline. Other encouraging examples include the improvement of skill levels through an innovative two-year District Management and Leadership Course in Eastern Cape Province. The course is organized through in-service, but awards the graduates an academic qualification. In the same province, supervision improved through the development and application of a supervisory manual that establishes the expected standards of work. The use of the manual assures an objective supervision based on positive reinforcement, and ensures that the obligations of the supervisee and the supervisor are documented in writing.

[Based on personal communication with Ms. Nomathemba Mazaleni and Dr. Jon Rohde, Equity project, Eastern Cape province, South Africa, and information in Martineau et al. 2003 [See [32]].]

\section{Ghana}

The Ghana Strengthening District Health Systems Initiative (SDHS) aimed to improve management at the decentralized levels. It prepared the ground for a successful and stable health sector reform process in Ghana. The approaches used, i.e. problem analysis and solving, team based training focusing on self-identified needs, and regular facilitated progress reviews and feedback, were critical for making districts better planners and advocates for their specific needs. As district capacity increased, regional and national supervisory levels began to demand more training for themselves in order to be better equipped to support the newly identified district needs.

An encouraging example of how innovative local decision-making can have a national impact comes from the Nkwanta District in the remote Northern Volta Region. The Nkwanta District team attended district health systems training at the Navrongo Health Research Center, exposing them to methods of research that had achieved health gains. Navrongo had had good results from using community health nurses, who lived within the communities they served, to deliver primary health care and family planning services. The Nkwanta District Director and his team decided to implement a similar scheme in their district, and the high level of decentralized decision making in Ghana allowed the Director to place community health nurses in particularly deprived sections of the Nkwanta district. This decision had such good results that it eventually became the basis for national policy. The methodology that emerged, Community Health Planning and Services (CHPS), now aims to increase access to health care in the whole country.

(Based on personal communication with Dr. Delanyo Dovlo, previously Director of Human Resources Development in the Ministry of Health, Ghana.)

\section{Indonesia}

Law 22/1999 on regional governments in Indonesia initiated a radical decentralization of powers over a large number of government functions. Central government civil servants who worked in a region were now brought together with local government personnel in a regional government structure. In the health sector, over a quarter of a million health personnel were transferred to regional governments. They included medical officers who had for many years been seconded to regional health offices, as well as hospital staff who were only now being transferred.

Almost 2.4 million civil servants in total were reassigned from the central to local governments. No other decentralizing country has undertaken such a massive transfer of staff. Its successful completion was one of the greatest achievements of Indonesia's transition to regional autonomy. The transfer did not involve a physical relocation for most staff, but was mainly a bureaucratic process. In fact, observers have commented that the fact that staff transfers were a routine task of the Civil Service Board was one of the main reasons for the success. While the scale of the transfers was enormous, the work required was not new, and the Civil Service Board was appropriately structured to undertake it.

The transition was not without huge challenges. Developing a staff list for each regional office took much longer than expected. Substantial differences initially existed between the lists of the central government and those in the local offices. Each staff member required a decree ordering his or her transfer. Each region, in turn, needed records of individual entitlements, such as leave and family allowances. The capacity of some regional offices of the Civil Service Board was grossly inadequate for a task of this magnitude. They had to await additional funding and the purchase of needed computer equipment.

Matters were complicated further in May 2000, when the central government approved a program to rationalize the pay of civil servants. This included a pay rise which the regions had not budgeted for, since they were unaware that it was coming. Late payment of the increases created labor disturbances that exposed flaws in the prepared staff lists. In a number of regencies, hundreds of health work- 
ers, for example, were found to be still on the provincial payroll.

Regions now have the power to hire, appoint, transfer and fire personnel. It is alleged that they tend to favor staff who originate from the same region. While no systematic research exists on the distribution of civil servants, available data from the Civil Service Board reveals a highly unequal distribution of health staff. Authority for training is also now with the regions. It is not clear what training regions are planning or undertaking, nor whether sufficient funds have been allocated for such training. What role the central government will play in human resource development is also yet to be determined. In the meantime, decentralized staff remain concerned about their removal from the career paths and opportunities that their prior employment status with the national government made possible.

[Based on Turner and Podger [33].]

\section{Mexico}

Mexico decentralized considerable powers over the health sector from the federal to the state governments. The aim was to increase health care accessibility and coverage, and some 116,000 health workers were transferred from federal to state employment. Three main strategies have been used to strengthen human resources, and develop the staff required to implement decentralized service delivery. First, federal initiatives, aimed at increasing service demand, are linked with considerations about the availability of appropriate staff at the state level. Second, staff qualifications are improved through training. Third, adjustments are sought in the legal framework governing labor matters.

Most health workers are reluctant to accept rural postings because the working conditions and quality of life compare unfavorably with what they are accustomed to in the urban areas. In order to meet the needs of underserved rural areas, the Ministry of Health provides scholarships to recent graduates in nursing, medicine and social work who agree to do their Social Service time in such areas. These efforts have, however, failed because of the shortage of both federal and state staff positions and funding. State governments have chosen to concentrate the available personnel in the state capitals. Federal employees tend also to be concentrated in state capitals directing federally funded health programs, rather than working at the municipal level. Municipalities therefore claim that decentralization has resulted in a new centralization at the state level.

Staff with qualifications appropriate to the positions they hold continue to be concentrated in the major urban cent- ers because of constraints in training capacity and competition for posts in the preferred urban locations. While 90 $\%$ of transferred physicians do meet the requirements for the posts they hold, $16 \%-31 \%$ of all medical, paramedical and administrative staff have not yet completed their studies to gain an appropriate qualification. Without such a qualification, they cannot be confirmed in their positions. It is the fully qualified health personnel, who obtain the positions in the major urban centers [34]. In response to the increased need for public health managers at state and municipal levels, state governments have attempted, but failed to persuade local universities and health institutes to provide post-graduate training and continuing education for these key personnel. Public health and management training remain centralized in the principal academic centers, located in the center of the country.

One of the most damaging results of decentralization is the fragmentation in labor policy. Most states hire personnel through (at least) two different mechanisms, i.e. 'federal' and 'state' contracts. These contracts result in quite different labor benefits and working conditions for personnel, with the consequence that two health workers who hold the same type of post and perform similar tasks may have very different earnings. The fragmented labor policy is a very divisive factor for labor relations at both the federal and state levels. Finding a solution remains one of Mexico's most important human resource challenges $[35,36]$.

[Based on information provided by Dr. Armando Arredondo and Mr. Emanuel Orozco, Health Systems Research Center, National Institute of Public Health, Cuernavaca, Mexico, including the referenced documents they cite.]

\section{Competing interests}

None declared.

\section{Acknowledgements}

Preparation of this paper was made possible with support from the Rockefeller Foundation. It was originally written for the Joint Learning Initiative (JLI) on Human Resources for Health and Development, presented in the JLI Working Group 3 meeting in May 2003 in Veyrier, France, and revised for publication.

\section{References}

I. Dussault G, Dubois C-A: Human resources for health policies: a critical component in health policies. Human Resources for Health 2003, I (I I-25 [http://www.human-resources-health.com/con tent/I/I/I].

2. Wang $Y$, Collins $C$, Tang S, Martineau T: Health system decentralization and human resources management in low and middle income countries. Public Administration and Development 2002, 22:439-453.

3. Bach S: Decentralization and privatization in municipal services: The case of the health services. Sectoral Activities Programme WorkingPaper WP.I64 Geneva: International Labour Organization; 2000. 
4. Kolehmainen-Aitken R-L: Decentralization and human resources: implications and impact. Human Resource Development Journal 1998, 2(I): I-16.

5. Buchan J: Health sector reform and human resources: lessons from the United Kingdom. Health Policy and Planning 2000, I 5(3):319-325.

6. Mills A, Bennett S, Russell S: The Challenge of Health Sector Reform: What Must Governments Do? New York: Palgrave; $200 \mathrm{I}$.

7. Bach S, Buchan J, Martineau T: MINSA-DFID Project: Human resource development and health sector reform. Ministry of Health, Government of Peru. London: IHSD 1999.

8. Tang SL, Bloom G: Decentralising rural health services: a case study in China. International Journal of Health Planning and Management 2000, I5:189-200.

9. Bossert T, Beauvais J, Bowser D: Decentralization of health systems: Four country case studies. Washington, DC: Partnerships for Health Reform; 2000.

10. Kolehmainen-Aitken R-L: Decentralisation and health workforce development. In Decentralization in a developing country: The experience of Papua New Guinea and its health service Edited by: Thomason JA, Newbrander WC, Kolehmainen-Aitken R-L. Canberra: The Australian National University; 1991:101-117.

II. Gong YL, Wilkers A, Bloom G: Health human resource development in rural China. Health Policy and Planning 1997, I 2(4):320-328.

12. International Labour Organization: Terms of employment and working conditions in health sector reforms. Report for discussion at the Joint Meeting on Terms of Employment and Working Conditions in Health Sector Reforms. Geneva 1998.

13. Brito P, Galin P, Novick M: Labor relations, employment conditions and participation in the health sector. Paper prepared for the WHO Workshop on Global Health Workforce Strategy. Annecy, France 2000. 9-12 December 2000

14. Martinez ], Martineau T: Introducing performance management in National Health Systems: Issues on policy and implementation. An IHSD Issues Note. London: Institute for Health Sector Development 200I.

15. Kolehmainen-Aitken R-L: Background note for the World Bank on decentralized personnel management in Uganda. Boston: Management Sciences for Health; 2000.

16. Tong $\mathrm{CH}$, Straussman JD, Broadnax WD: Civil service reform in the People's Republic of China: case studies of early implementation. Public Administration and Development 1999, 19:193-206.

17. Saide MAO, Stewart DE: Decentralization and human resource management in the health sector: a case study (1996-1998) from Nampula province, Mozambique. International Journal of Health Planning and Management 2001, I 6:155-168.

18. Campos-Outcalt $D$, Kewa $K$, Thomason J: Decentralization of health services in Western Highlands Province, Papua New Guinea: an attempt to administer health service at the subdistrict level. Social Science and Medicine 1995, 40(8): 1091-1098.

19. Solter S: Does decentralization lead to better-quality services. In Myths and realities about the decentralization of health systems Edited by: Kolehmainen-Aitken R-L. Boston: Management Sciences for Health; 1999.

20. Perez J, Alfiler MC, Victoriano M: Managing transition dilemmas in the early years of devolution in the Philippines: A study for the WHO project on decentralization and health systems change. 1995

21. Newbrander WC, Aitken IW, Kolehmainen-Aitken R-L: Performance of the health system under decentralization. In Decentralization in a Developing Country: The Experience of Papua New Guinea and Its Health Service Edited by: Thomason J, Newbrander WC, Kolehmainen-Aitken R-L. Canberra: Australian National University; 1991:64-75.

22. Bach S: HR and new approaches to public sector management: Improving HRM capacity. Paper prepared for the WHO Workshop on Global Health Workforce Strategy. Annecy, France 2001.

23. Van Lerberghe $W$, Adams O, Ferrinho P: Human resources impact assessment. Bulletin of the World Health Organization 2002, 80(7):525.

24. Brito Quintana P: Desafios y problemas de la gestion de recursos humanos de salud en las reformas sectoriales. Washington, DC: Organización Panamericana de la Salud; Undated [http:// www.opas.org.br/rh/admin/documentos/plg02010.pdf].
25. Sia I, del Prado G, Diwa B, Estabilo VB, Israel L, Lorenzo FM, Santos B: Country study: Philippines. In Public Service Reforms and their Impact on Health Sector Personnel. Berlin: DSE 2000.

26. Tang SL, Bloom G, Feng XS, Lucas H, Gu XY, Segall M: Financing Health Services in China: Adapting to Economic Reform. Brighton: Institute of Development Studies 1994.

27. Okuonzi S, Lubanga FXK: Decentralization and Health System Change: Uganda Case Study Geneva: World Health Organization; 1995.

28. Kolehmainen-Aitken R-L: Human resources development under decentralization. In Myths and realities about the decentralization of health systems Edited by: Kolehmainen-Aitken R-L. Boston: Management Sciences for Health; 1999:39-64.

29. Biscoe G: Human resources: the political and policy context. Paper prepared for the Global Health Workforce Strategy Group Geneva: World Health Organization; 200I.

30. Kolehmainen-Aitken R-L: Defining human resource responsibilities in the era of health sector reform. Presentation at the American Public Health Association meeting. Boston 2000.

31. Organizacíon Panamericana de la Salud: Factores restrictivos para la descentralización en recursos humanos. Programa de Desarrollo de Recursos Humanos. Washington DC: OPS/OMS 1999.

32. Martineau T, Tang S, Chen L, Xiaoyun L, Zhan S, Makhanya N, Magongo B: Decentralisation and the Impact on Human Resource Management in China and South Africa. SSR Project R7652 Final Report Liverpool: Liverpool School of Tropical Medicine; 2003.

33. Turner M, Podger O, Sumardjono M, Tirthayasa WK: Decentralization in Indonesia: Redesigning the State Canberra: Asia Pacific Press at the Australian National University; 2003.

34. Arredondo A, Parada I, Orozco E, García E, Atrixco R, Allende T, Cicero M, Flores G: El Financiamiento a partir de la Descentralización del Sistema de Salud en México, 1990-2000: Cambios, Tendencias y Evidencias. Cuernavaca: Instituto Nacional de Salud Pública 2002.

35. SSA: Diagnóstico situacional de los recursos humanos en el primer nivel de atención y propuesta de reordenamiento. In Consejo Nacional de Salud. Hacia la Federalización de la Salud en México. México 21998.

36. Arredondo A: Federalismo y salud: Estudio de caso del sistema de salud en Mexico. In Federalismo y Politicas de Salud, Descentralización y Relaciones Intergubernamentales Desde una Perspectiva Internacional. Québec: Forum of Federations [Instituto Nacional sobre el Federalismo] 2003
Publish with Biomed Central and every scientist can read your work free of charge

"BioMed Central will be the most significant development for disseminating the results of biomedical research in our lifetime. "

Sir Paul Nurse, Cancer Research UK

Your research papers will be:

- available free of charge to the entire biomedical community

- peer reviewed and published immediately upon acceptance

- cited in PubMed and archived on PubMed Central

- yours - you keep the copyright
BioMedcentral 